\title{
PENGARUH DIGITAL MARKETING, PERCEIVED QUALITY DAN PERSONAL SELLING TERHADAP PENJUALAN PRODUK TAHU (STUDI KASUS : PENGRAJIN TAHU DI KEDIRI)
}

\section{Puji Astuti}

Manajemen Fakultas Ekonomi, Universitas Kadiri puji_astutik@unik-kediri.ac.id

\section{Daniel}

Manajemen Fakultas Ekonomi, Universitas Kadiri daniel_fe@unik-kediri.ac.id

\section{Sony Fridayanto}

Manajemen Fakultas Ekonomi, Universitas Kadiri sonyfrid_77@yahoo.com

\section{Herman Kusbandono}

Manajemen Fakultas Ekonomi, Universitas Kadiri herman.kusbandono81@yahoo.com

\begin{abstract}
This study aims to determine the role of digital marketing, perceived quality and personal selling on the sale of tofu products in the city of Kediri. This study used 60 respondents, namely tofu craftsmen, to be given a questionnaire. They were taking respondents using probability sampling techniques. This research method uses linear regression statistical analysis techniques. They are starting with the validity test, reliability test, classical assumption test, multiple linear regression test, partial test, simultaneous test, and determination coefficient. This study's results are digital marketing has no effect on product sales partially, while perceived quality and personal selling have an impact on product sales partially. Meanwhile, simultaneously all independent variables simultaneously influence the dependent variable. The success rate of this study was $64.8 \%$. This research can be increased again, the role of the variables to have a high level of influence by filling out the questionnaire in an educational manner according to the conditions of observation that have been made.
\end{abstract}

Keywords: Digital Marketing, Perceived Quality, Personal Selling, Sales

Corresponding author:

Email Address : puji astutik@unik-kediri.ac.id (Kediri, Jawa Timur)

Received 14 Nopember 2020, Accepted 10 Pebruari 2021, Published 22 Pebruari 2021

\section{PENDAHULUAN}

Ddalam sebuah organisasi di masa krisis ini harus dapat menyesuaikan cara memasarkan produknya dan memahami risiko risiko yang dihadapinya. Oleh sebab itu, beberapa peran strategi yang digunakan yaitu business to business karena akan melibatkan mitra bisnis secara efektif kepada relasinya berupa calon konsumen, konsumen lama dan orang lain. Ketika dilakukan pengambilan keputusan untuk melakukan business to business harus kuat dalam hal kooperatif dan kompetitif untuk meningkatkan kinerja organisasi. Terkait masa pandemi ini, banyak organisasi yang dibidang jasa maupun barang sulit melakukan pemasaran dengan banyak kendala yang dihadapi (Crick \& Crick, 2020).

Masa pandemi ini, belum diketahui pasti kapan berakhirnya. Oleh sebab itu, dampak yang paling berat adalah menurunnya 
perekonomian diseluruh negara, kemudian masyarakat juga ikut terpengaruh dalam hal pemecatan hubungan kerja, segala bisnis perlu memikirkan langkah baru untuk mempertahankan usaha yang dirintis dan dapat mengatasi masalah - masalah yang dihadapi (Donthu \& Gustafsson, 2020). Terkait dengan masalah bisnis yang terjadi, konsumen yang telah terbiasa menggunakan suatu produk akan lambat laun berusaha mengurangi konsumsi, disebabkan menurunnya pendapatan karena terdampak pandemi di lokasi pekerjaannya (Kannan, 2020).

Secara luas, dampak yang ditimbulkan dalam hal bisins, transportasi, e-commerce dengan pemikiran yang baru, dimunculkan pemasaran online sebagai senjata bagi pebisnis agar tetap meningkatkan penjualan produknya (Patel \& Malpani, 2020). Selain itu, industri pariwisata juga terkena dampak yang paling besar dari bidang lainnya (Hong et al., 2020). Menurut (He \& Harris, 2020), sejak adanya masa pandemi dapat memberikan pengaruh negatif pada corporate social responsibility dan pemasaran. Terkait hal ini, sebuah keputusan dalam melakukan bisnis perlu diperhitungan kembali dan ditinjau kembali terkait dengan corporate social responsibility (Djunaedi, 2016). Ditinjau dari segi pemasaran juga akan memiliki langkah - langkah strategi yang perlu dirumuskan sebelumnya (Indrasari, 2017; Komari, Sularso, \& Sumiato, 2019).

Pemasaran saat ini meliputi barang dan jasa menggunakan prinsip 7P, sehingga diera pandemi ada kendala - kendala yang perlu diidentifikasi (Komari, Laely, \& Panjaitan, 2017; Komari et al., 2019). Menurut (Panjaitan \& Djunaedi, 2017), produk yang akan dipasarkan perlu dikaji untuk penentuan spesifikasi agar berbeda dengan kompetitor. Menurut (Panjaitan \& Laely, 2017) keputusan didalam merencanaan teknik pemasaran perlu melibatkan variabel mediasi untuk mengetahui pengaruh secara langsung maupun tidak langsung. Diperlukan peran konsumen untuk mempercepat langkah dalam mengetahui pengaruh tersebut (Andarini, Laely, \& Laily, 2020) dan alternatif strategi secara terencana dan sesuai target pemasaran yang dijangkau(Laely, 2020).

Dalam penelitian yang dilakukan oleh (Komari, 2017; Laely \& Komari, 2017), didalam peran jangkauan pemasaran dari sebuah produk diperlukan manajerial dan peran lingkungan yang dapat memahami langkah untuk menuju visi dan misi perusahaan. Dampak pandemi yang menjadi masalah yaitu pada usaha mikro dan kecil, dikarenakan selain mengurangi pendapatan juga perlu mengurangi tenaga kerja (Purnamaningsih \& Djunaidi, 2018). Salah satu tempat yang dijadikan penelitian adalah UMKM tahu yang berada di kota dan kabupaten Kediri. Masalah pertama yaitu omzet UMKM tersebut rata- rata menurun sebesar $60 \%$ dari omzet sebelum pandemi. Masalah kedua, agen yang menjadi distributor mengurangi persediaan karena sangat sedikit yang melakukan kunjungan - kunjungan ke pusat oleh - oleh, disebabkan banyak masyarakat yang tidak diperbolehkan bepergian jauh sesuai dengan aturan protokol kesehatan waktu itu (He \& Harris, 2020).

Masalah ketiga, susahnya mencari bahan baku karena penyuplai kedelai juga merasakan dampak pandemi. Masalah keempat, jika ada bahan baku pasti harganya juga mahal. Oleh sebab itu, para pengrajin tahu tersebut mengeluh karena dampak yang diterima tidak tanggung - tanggung. Sejak April 2020 sampai dengan Juli 2020, terjadi pengurangan tenaga kerja dan dampak lainnya adalah omzet yang lambat laun menurun (Setyawan \& Lestari, 2020). Penyedia persediaan tahu yang mengambil dari para pengrajin tahu, dengan terpaksa mengurangi persediaan untuk mengantisipasi tidak lakunya produk tahu yang telah dijajakan pada masing - masing pusat oleh - oleh.

Beberapa tempat di kediri, memang melakukan hal itu demi bertahan akan kelangsungan hidup pekerja dan usahanya (Pater \& Cristea, 2018; Tavassoli, Saen, \& Zanjirani, 2020). Langkah yang digunakan untuk meningkatkan penjualan produk tahu tersebut didalam penelitian ini menggunakan digital marketing (Andrew, 2016), perceived quality (Das, 2014) dan personal selling (Ocon \& Alvarez, 2014). Penggunaan variabel bebas tersebut akan diuji untuk mengetahui pengaruhnya terhadap penjualan produk (Husnus \& Pratiwi, 2014). Dari permasalahan tersebut tujuan penelitian ini untuk mengetahui pengaruh digital marketing, perceived quality dan personal selling terhadap penjualan produk tahu secara parsial dan simultan

Manfaat penelitian untuk pengrajin tahu sebagai langkah meningkatkan cara penjualan produk dimasa pendemi, kemudian sebagai 
masukan untuk mengetahui seluk beluk digital marketing, perceived quality dan personal selling. Kemudian manfaat instansi adalah sebagai bahan ajar dibidang manajemen dan untuk sebagai sumber informasi terkait keberlangsungan hidup pengrajin tahu dimasa pandemic.

\section{METODE PENELITIAN}

\section{Lokasi Penelitian, Populasi dan Sampel}

Penelitian ini menuju beberapa lokasi di area kota dan kabupaten Kediri, untuk mengetahui jumlah pengrajin tahu. Jumlah pengrajin tahu yang dituju ke lokasi menggunakan teknik eksperimen dan obyektif, dikarenakan dari beberapa sumber yang digunakan belum cukup akurat. Oleh sebab itu, kelemahan yang menjadi kendala adalah penentuan besar populasi di area kota dan kabupaten kediri. Kegiatan observasi eksperimen obyektif dilakukan sejak bulan Maret 2020 sampai dengan Juli 2020.

Populasi adalah jumah suatu obyek dalam satu area yang memiliki kesamaan dalam hal karakteristik yang digunakan untuk melakukan pengambilan kesimpulan (Sudharta, n.d.). Penelitian ini menggunakan populasi pengrajin tahu yang berada di kota Kediri yang berjumlah sebanyak 148 pengrajin tahu dengan penggunaan kriteria. Kriteria yang digunakan adalah pengrajin tahu yang dilokasi jualan memiliki tempat untuk memproduksi tahu baik skala kecil maupun besar. Dalam hal ini, kemudian dilakukan penentuan besar sampel penelitian (Budijanto, 2013).

Sampel yang digunakan dalam penelitian ini menggunakan rumus Slovin, sebagai berikut (Gilad \& Slovin, 2015) :

$$
n=\frac{N}{1+N e^{2}}
$$

Keterangan :

$\mathrm{n}=$ jumlah sampel penelitian

$\mathrm{N}=$ jumlah populasi

$\mathrm{e}=$ margin of error $(10 \%)$

Dalam hal ini, sampel yang digunakan dilakukan perhitungan dengah hasil sebagai berikut :

$$
n=\frac{148}{1+\left(148 \times\left(0,1^{2}\right)\right)}=59,67 \text { responden }
$$

Sampel yang didapatkan sebesar 59,67 responden yang dibulatkan menjadi 60 responden. Dalam hal ini, responden yang digunakan dalam penelitian ini sebesar 60 responden. Dalam sampel penelitian ini, menggunakan teknik probability sampling dengan cara memberikan peluang yang sama dan dipilih sampel penelitian secara acak (Dahlan, 2010).

\section{Subjek dan Objek Penelitian}

Dalam penelitian ini, subyek yang digunakan dalam penelitian ini adalah pengrajin tahu di kota dan kabupaten Kediri. Sedangkan obyek penelitian adalah penjualan produk tahu. Sedangkan analisis faktor menggunakan variabel digital marketing, Perceived quality dan Personal Selling.

\section{Variabel Operasional}

Terkait dengan variabel operasional digunakan sebagai gambaran pada konsep yang digunakan dalam penelitian, kemudian variabel di identifikasi menggunakan beberapa indikator. Tiap variabel tersebut menggunakan skala likert dan diberikan skor dengan penilaian $1=$ sangat tidak setuju ; $2=$ tidak setuju ; $3=$ netral $; 4=$ setuju dan $; 5=$ sangat setuju.

\begin{tabular}{|c|c|c|}
\hline Variabel & Indikator & Skala \\
\hline $\begin{array}{c}\text { Digital Marketing } \\
\left(\mathrm{X}_{1}\right)\end{array}$ & $\begin{array}{l}\text { 1. Site Design } \\
\text { 2. Incentive Program } \\
\text { 3. Interactive }\end{array}$ & Likert \\
\hline $\begin{array}{l}\text { Perceived quality } \\
\qquad\left(\mathrm{X}_{2}\right)\end{array}$ & $\begin{array}{ll}\text { 1. } & \text { Durability } \\
\text { 2. } & \text { Features } \\
\text { 3. } & \text { Aesthetics } \\
\text { 4. } & \text { Reliability } \\
\text { 5. } & \text { Conformance } \\
\end{array}$ & Likert \\
\hline $\begin{array}{l}\text { Personal Selling } \\
\left(\mathrm{X}_{3}\right)\end{array}$ & $\begin{array}{ll}\text { 1. } & \text { Personal } \\
\text { 2. } & \text { Confrontation } \\
\text { 3. } & \text { Responsif } \\
& \text { Relationship } \\
\text { Cultivation }\end{array}$ & Likert \\
\hline $\begin{array}{l}\text { Penjualan Produk } \\
\text { (Y) }\end{array}$ & $\begin{array}{ll}\text { 1. } & \text { Karakteristik } \\
\text { Barang } \\
\text { 2. Jasa Yang } \\
\text { Ditawarkan } \\
\text { 3. Kesesuaian Harga }\end{array}$ & Likert \\
\hline
\end{tabular}

\section{Tabel 1. Variabel Operasional}

(Sumber: Olah data, 2020)

\section{Jenis dan Sumber Data}

Pengelompokkan jenis dan sumber data digunakan untuk memahami data apa saja yang diperlukan dalam penelitian, sehingga dapat dikelompokkan dan diketahui sumber data yang diperoleh (Maksum, 2012). Diperlukan pemetaan jenis dan sumber data dalam tabel agar mudah pemahaman di setiap identifikasinya, sebagai berikut (Suryana, 2010). 
Tabel 2. Jenis dan Sumber Data

\begin{tabular}{|c|l|c|}
\hline No. & \multicolumn{1}{|c|}{ Nama data } & \multicolumn{1}{c|}{ Jenis data } \\
\hline 1 & Wawancara & Data Primer \\
\hline 2 & $\begin{array}{l}\text { Penyebaran dan } \\
\text { penarikan kuesioner }\end{array}$ & Data primer \\
\hline 3 & Studi literatur & Sekunder \\
\hline
\end{tabular}

(Sumber : Olah data,2020)

\section{Teknik Pengumpulan Data}

Tahapan pengumpulan data diawali dengan kegiatan observasi, yaitu: melakukan tinjauan langsung ke lokasi penelitian yaitu pengrajin tahu di kabupaten dan kota kediri yang sudah dijadikan sampel pada penelitian ini (Sugiyono, 2010). Dilanjutkan kegiatan wawancara untuk menggali informasi agar penyusunan kuesioer menjadi akurat terkait variabel yang digunakan (Alfianika, 2018). Jika kegiatan wawancara telah selesai, disusun kuesioner menggunakan variabel yang dapat mewakili kata kunci didalam penelitian agar terwujud hasil penelitian sesuai dengan kajian observasi yang diharapkan (Hasanah, 2017). Rangkaian kegiatan tersebut, diperlukan kajian pustaka untuk memperkuat dugaan hasil penelitian dan juga sebagai acuan teoritis agar penelitian memiliki dasar yang kuat terkait hasil yang dicapai (Sugiyono, 2014).

\section{Teknik Analisis Data}

Dalam teknik analisis data menggunakan metode statistik regresi linier sebagai berikut (Sulistyono \& Sulistiyowati, 2018) :

1. Uji Validitas (Sulistyono \& Sulistiyowati, 2018) dan Uji Reliabilitas (Syafruddin, Hakim, \& Despa, 2014).

\section{Tabel 3. Kriteria dan Nilai Cronbach Alpha}

\begin{tabular}{|c|c|}
\hline Nilai Cronbach Alpha & Kriteria \\
\hline$<0,200$ & Sangat rendah \\
\hline $0,200-0,399$ & Rendah \\
\hline $0,400-0,599$ & Cukup \\
\hline $0,600-0,799$ & Tinggi \\
\hline $0,800-1,000$ & Sangat tinggi \\
\hline
\end{tabular}

(Sumber : (Andriani, 2017))

2. Uji Asumsi Klasik yaitu langkah untuk mengetahui nilai estimasi yang terbaik dengan uji - uji didalamnya sebagai berikut (Priyatno, 2014):

a. Uji Normalitas menggunakan uji Kolmogorov-Smirnov (Lawendatu, Kekenusa, \& Hatidja, 2014). b. Uji Autokorelasi (Janie, 2012).

c. Uji Multikolinieritas

d. Uji Heterokesdastisitas

e. Uji Linieritas

3. Uji Regresi Linier Berganda menggunakan persamaan regresi linier berganda sebagai berikut (A Field, 2013)

- $Y=a+b_{1} X_{1}+b_{2} X_{2}+b_{3} X_{3}$

4. Uji $\mathrm{T}$ berfungsi sebagai cara untuk mengetahui pengaruh variabel dependen dengan variabel independen dengan mengacu hipotesis sebagai berikut (Andy Field, 2013):

- $\mathrm{H}_{0}$ ditolak jika nilai sig. > 0,05 atau $\mathrm{T}_{\text {tabel }}>\mathrm{T}_{\text {hitung }}$

- $\mathrm{H}_{\mathrm{a}}$ diterima jika nilai sig. $<0,05$ atau $\mathrm{T}_{\text {hitung }}>\mathrm{T}_{\text {tabel }}$

5. Uji $F$ berfungsi sebagai langkah untuk mengetahui tingkat pengaruh antara variabel dependen dengan variabel independen secara bersama -sama dengan ketentuan :

a. Jika nilai $\operatorname{Sig}<0,05$ dan $F_{\text {hitung }}>F_{\text {tabel, }}$, diambil jawaban terdapat nilai simultan variabel bebas (X) berpengaruh signifikan terhadap variabel terikat $(\mathrm{Y})$.

b. Jika nilai Sig $>0,05$ dan $F_{\text {hitung }}<F_{\text {tabel, }}$ diambil jawaban nilai simultan variabel bebas (X) tidak ada pengaruh signifikan terhadap variabel terikat $(\mathrm{Y})$.

6. $R$ Square digunakan untuk mendapatkan prosentase dari keberhasilan penelitian yang telah dilakukan. Acuan yang digunakan adalah melihat nilai Adjusted $R$ Square pada nilai koefisien determinasi.

\section{HASIL DAN PEMBAHASAN \\ Karakteristik Responden}

Berdasarkan penyebaran dan penarikan kuesioner yang telah dilakukan, didapatkan hasil dari karakteristik responden dari sampel penelitian ini. Ditinjau dari jenis kelamis, pengrajin tahu lebih dominan perempuan dengan jumlah sebesar 17 orang. Pengrajin tahu adalah turun temurun. Oleh sebab itu, lebih dominan perempuan yang menjadi generasi selanjutnya, pengrajin tahu tersebut memiliki 
tenaga kerja yang menjalankan roda perputaran usaha, sedangkan responden laki - laki sebanyak 13 orang, di mana responden juga sebagai pengrajin yang memiliki tenaga kerja.

\section{Tabel 4. Karakteristik Responden}

\begin{tabular}{|l|c|c|}
\hline \multicolumn{1}{|c|}{ Karakteristik } & Jumlah & Persen \%) \\
\hline Jenis Kelamin & & \\
\hline a. Laki - laki & 13 & 21,7 \\
\hline b. Perempuan & 17 & 78,3 \\
\hline Usia & & \\
\hline a. <30 Tahun & 11 & 18,3 \\
\hline b. >30 Tahun & 49 & 81,7 \\
\hline Pendidikan & & \\
\hline a. SD & 4 & 6,7 \\
\hline b. SMP & 16 & 26,7 \\
\hline c. SMA & 40 & 66,7 \\
\hline Pendapatan & & \\
\hline a. <1 Juta & 42 & 70 \\
\hline b. 1 s/d 3 Juta & 18 & 30 \\
\hline Lama Usaha & & \\
\hline a. <5 Tahun & 10 & 16,7 \\
\hline b. >5 Tahun & 50 & 83,3 \\
\hline (Sumber : Olah data,
\end{tabular}

(Sumber : Olah data, 2020)

Tinjauan pendidikan lebih dominan lulusan SMA dengan jumlah sebesar 40 orang yang memiliki prosentase sebesar $66,7 \%$. Jika ditinjau dari lama usaha, lebih dominan lama usaha $>5$ tahun dengan jumlah pengrajin tahu sebanyak 50 lokasi. Hal ini dapat dibuktikan karena lokasi pengrajin tahu yang diteliti sudah menginjak generasi dua bahkan ada yang menginjak generasi tiga. Sedangkan lama usaha $<5$ Tahun sebanyak 10 lokasi, dikarenakan dapat dikatakan masih rintisan usaha tahu baru dan ada yang membuka cabang ditempat lain karena sudah memiliki pengalaman dibidang proses pembuatan tahu.

\section{Analisis Statistik}

Dalam analisis statistik, beberapa uji yang dilakukan diawali dengan uji validitas, uji reliabilitas dan asumsi klasik dengan rekapitulasi sebagai berikut :

Tabel 5. Keterangan Uji Validitas dan Kriteria Uji Reliabilitas

\begin{tabular}{|c|c|c|c|c|c|}
\hline Indikator & $\begin{array}{c}\mathrm{R} \\
\text { tabel } \\
(\mathrm{n}-2)\end{array}$ & $\begin{array}{c}\mathrm{R} \\
\text { hitung }\end{array}$ & Ket & $\begin{array}{l}\text { Nilai } \\
\text { Cron } \\
\text { bach } \\
\text { Alpha }\end{array}$ & Kriteria \\
\hline X11 & 0,254 & 0,854 & Valid & \multirow{3}{*}{0,720} & \multirow{3}{*}{$\begin{array}{c}\text { Reliabel } \\
\text { Tinggi }\end{array}$} \\
\hline $\mathrm{X} 12$ & 0,254 & 0,885 & Valid & & \\
\hline $\mathrm{X} 13$ & 0,254 & 0,660 & Valid & & \\
\hline
\end{tabular}

\begin{tabular}{|c|c|c|c|c|c|}
\hline Indikator & $\begin{array}{l}\mathrm{R}_{\text {tabel }} \\
(\mathrm{N}-2)\end{array}$ & $\begin{array}{c}\mathrm{R} \\
\text { hitung }\end{array}$ & Ket & $\begin{array}{l}\text { Nilai } \\
\text { Cron } \\
\text { bach } \\
\text { Alpha }\end{array}$ & Kriteria \\
\hline $\mathrm{X} 21$ & 0,254 & 0,876 & Valid & \multirow{5}{*}{0,829} & \multirow{5}{*}{$\begin{array}{c}\text { Reliabel } \\
\text { Sangat } \\
\text { Tinggi }\end{array}$} \\
\hline $\mathrm{X} 22$ & 0,254 & 0,898 & Valid & & \\
\hline $\mathrm{X} 23$ & 0,254 & 0,860 & Valid & & \\
\hline $\mathrm{X} 24$ & 0,254 & 0,385 & Valid & & \\
\hline $\mathrm{X} 25$ & 0,254 & 0,842 & Valid & & \\
\hline X31 & 0,254 & 0,721 & Valid & \multirow{3}{*}{0,512} & \multirow{3}{*}{$\begin{array}{c}\text { Reliabel } \\
\text { Cukup }\end{array}$} \\
\hline X32 & 0,254 & 0,693 & Valid & & \\
\hline X33 & 0,254 & 0,723 & Valid & & \\
\hline Y1 & 0,254 & 0,876 & Valid & \multirow{3}{*}{0,824} & \multirow{3}{*}{$\begin{array}{l}\text { Reliabel } \\
\text { Sangat } \\
\text { Tinggi }\end{array}$} \\
\hline $\mathrm{Y} 2$ & 0,254 & 0,901 & Valid & & \\
\hline Y3 & 0,254 & 0,800 & Valid & & \\
\hline
\end{tabular}

Tabel di atas disimpulkan bahwa seluruh item kuesinoer dinyatakan valid dan reliabel.

\section{Tabel 6. Rekapitulasi Uji Asumsi Klasik}

\begin{tabular}{|c|c|c|c|}
\hline $\begin{array}{c}\text { Jenis } \\
\text { Asumsi } \\
\text { Klasik }\end{array}$ & $\begin{array}{c}\text { Dasar } \\
\text { Keputusan }\end{array}$ & $\begin{array}{l}\text { Nilai } \\
\text { Hitung }\end{array}$ & Keterangan \\
\hline $\begin{array}{l}\text { Uji } \\
\text { Normalitas }\end{array}$ & $\begin{array}{l}\text { Kolmogorov } \\
\text { Smirnov } \\
\text { Test Nilai } \\
\text { Asymp. Sig. } \\
(2 \text {-tailed) }> \\
0,05\end{array}$ & 0,200 & $\begin{array}{l}\text { Data } \\
\text { berdistribusi } \\
\text { normal }\end{array}$ \\
\hline $\begin{array}{l}\text { Uji Auto } \\
\text { korelasi }\end{array}$ & $\begin{array}{l}\text { Nilai durbin } \\
\text { watson } \\
\text { antara } 1,55 \\
-2,46\end{array}$ & 1,648 & $\begin{array}{l}\text { Data terjadi } \\
\text { autokorelasi }\end{array}$ \\
\hline $\begin{array}{l}\text { Uji Multi } \\
\text { kolinieritas }\end{array}$ & $\begin{array}{l}\text { Nilai VIF } \\
\text { antara } 1,00 \\
-10,000\end{array}$ & $\begin{array}{l}(\mathrm{X} 1) \\
1,151 \\
(\mathrm{X} 2) \\
1,440 \\
(\mathrm{X} 3) \\
1,559\end{array}$ & $\begin{array}{l}\text { Data tidak } \\
\text { terjadi multi } \\
\text { kolinieritas }\end{array}$ \\
\hline $\begin{array}{l}\text { Uji Hetero- } \\
\text { skedasitas }\end{array}$ & $\begin{array}{l}\text { Nilai } \\
\text { Signifikan } \\
\text { Coefficients } \\
\text { B >0,05 } \\
\text { Tidak akan } \\
\text { terjadi } \\
\text { hetero } \\
\text { kesdas tas }\end{array}$ & $\begin{array}{c}\mathrm{X} 1)- \\
0,008 \\
(\mathrm{X} 2) \\
0,300 \\
(\mathrm{X} 3) \\
0,770\end{array}$ & $\begin{array}{l}\text { (X1) Terjadi } \\
\text { hetero } \\
\text { kesdasitas } \\
\text { (X2) Tidak } \\
\text { terjadi hetero } \\
\text { kesdasitas } \\
\text { (X3) Tidak } \\
\text { Terjadi } \\
\text { hetero- } \\
\text { kesdasitas }\end{array}$ \\
\hline $\begin{array}{l}\text { Uji } \\
\text { Linieritas }\end{array}$ & $\begin{array}{l}\text { Nilai } \\
\text { Deviation } \\
\text { from } \\
\text { Linearity } \\
\text { ANOVA } \\
\text { Tabel F } \\
\text { Sig. > } 0,05\end{array}$ & $\begin{array}{c}(\mathrm{X} 1)^{*} \\
(\mathrm{Y}) \\
0,379 \\
(\mathrm{X} 2)^{*} \\
(\mathrm{Y}) \\
0,851 \\
(\mathrm{X} 3)^{*} \\
(\mathrm{Y}) \\
0,664\end{array}$ & $\begin{array}{l}\text { Pada variabel } \\
(\mathrm{X} 1),(\mathrm{X} 2) \\
\text { dan }(\mathrm{X} 3) \\
\text { memiliki } \\
\text { hubungan } \\
\text { dengan } \\
\text { variabel Y }\end{array}$ \\
\hline
\end{tabular}

(Sumber : Olah data, 2020)

Uji asumsi klasik memiliki berbagai uji didalamnya. Dari keterangan hasil pengujian di 
atas dapat disimpulkan bahwa tidak terjadi masalah dalam uji asumsi klasik sehingga dapat dilajutkan pengujian berikutnya. Model regresi regresi linier berganda yang didapatkan adalah $\mathrm{Y}=3,042+(-0,008) \mathrm{X} 1+0,300 \mathrm{X} 2+0,770 \mathrm{X} 3$. Model dapat dijelaskan sebagai berikut:

1. Nilai konstan sebesar 3,042. Dalam hal ini, penjualan produk $(\mathrm{Y})$ memiliki peran terhadap digital marketing (X1), perceived quality (X2) dan personal selling (X3) sebesar 3,402 satuan ketika tidak beraktivitas.

2. Nilai digital marketing (X1) sebesar (0,008), di mana digital marketing (X1) melakukan aktivitasya akan meningkatkan penjualan produk sebesar $-0,008$ satuan, dengan catatan variabel perceived quality (X2) dan personal selling (X3) bernilai konstan sebesar 3,042.

3. Nilai perceived quality (X2) sebesar 0,300 , di mana perceived quality (X2) melakukan aktivitasnya akan meningkatkan penjualan produk sebesar 0,300 satuan, dengan catatan variabel terhadap digital marketing (X1) dan personal selling (X3) bernilai konstan sebesar 3,042.

4. Nilai personal selling (X3) sebesar 0,770 , di mana personal selling (X3) melakukan aktivitasnya akan meningkatkan penjualan produk sebesar 0,770 satuan, variabel digital marketing (X1) dan perceived quality (X2) bernilai 3,042 .

Tabel 7. Model Regresi dan Uji Parsial

\begin{tabular}{|c|c|c|c|c|}
\hline Model & $\begin{array}{c}\text { Coefficients } \\
\text { B }\end{array}$ & $\begin{array}{c}\text { Std. } \\
\text { Error }\end{array}$ & $\mathrm{T}$ & Sig. \\
\hline Constant & 3,042 & 15,643 & 0,194 & 0,846 \\
\hline $\begin{array}{c}\text { Digital } \\
\text { Marketing } \\
\text { (X1) }\end{array}$ & $-0,008$ & 0,224 & $\begin{array}{c}- \\
0,036\end{array}$ & 0,971 \\
\hline $\begin{array}{c}\text { Perceived } \\
\text { Quality } \\
\text { (X2) }\end{array}$ & 0,300 & 0,104 & 2,874 & 0,006 \\
\hline $\begin{array}{c}\text { Personal } \\
\text { Selling } \\
\text { (X3) }\end{array}$ & 0,770 & 0,117 & 6,605 & 0,000 \\
\hline
\end{tabular}

(Sumber : Olah data, 2020)

Dalam uji T, variabel independen akan di uji dengan variabel dependen secara parsial. Pengujian dilakukan untuk mengetahui variabel independen manakah yang memiliki pengaruh sebagai faktor yang mempengaruhi variabel dependen. Hasil uji t diuraikan sebagai berikut :
1. T hitung dari digital marketing (X1) sebesar $(-0,036)$ dengan signifikansi 0,971 . Artinya nilai $\mathrm{T}$ hitung lebih kecil dari nilai $\mathrm{T}$ tabel sebesar 2,003 dan nilai signifikansi > 0,05. Diambil kesimpulan digital marketing (X1) tidak memiliki pengaruh terhadap penjualan produk dan tidak signifikan, dengan dasar $\mathrm{T}$ hitung < $\mathrm{T}$ tabel dan nilai signifikansi > 0,05 .

2. T hitung dari perceived quality (X2) sebesar 2,874 dengan signifikansi 0,006. Artinya nilai $\mathrm{T}$ hitung lebih besar dari nilai Ttabel sebesar 2,003 dan nilai signifikansi < 0,05. Diambil kesimpulan perceived quality (X2) memiliki pengaruh terhadap penjualan produk dan signifikan, dengan dasar Thitung $>$ Ttabel dan nilai signifikansi $<0,05$.

3. T hitung dari personal selling (X3) sebesar 6,605 dengan signifikansi sebesar 0,000. Artinya nilai $\mathrm{T}$ hitung lebih besar dari Ttabel sebesar 2,003 dan nilai signikansi < 0,05. Diambil kesimpulan personal selling (X3) memiliki pengaruh terhadap penjualan produk dan signifikan, dengan dasar Thitung $>\mathrm{T}$ tabel dan nilai signifikansi $<0,05$.

\section{Tabel 8. Uji Simultan dan Nilai Koefisien Determinasi}

\begin{tabular}{|c|c|c|}
\hline $\mathrm{F}$ & Sig. & Adjusted $R$ Square \\
\hline 37,175 & 0,000 & 0,648 \\
\hline
\end{tabular}

(Sumber : Olah data, 2020)

Hasil perhitungan nilai $\mathrm{F}$ hitung sebesar 37,175 > F tabel sebesar 2,77. Dinyatakan digital marketing (X1), perceived quality (X2) dan personal selling (X3) memilki pengaruh secara simultan terhadap penjualan produk $(\mathrm{Y})$. Tingkat keberhasilan penelitian ini dapat dilihat pada nilai Adjusted $R$ Square sebesar 0,648. Nilai tersebut sangat tinggi karena asumsi peneliti adalah tingkat keberhasilan harus melebihi 50\%. Oleh sebab itu, nilai 0,648 dinyatakan persentase menjadi $64,8 \%$. Jika ditinjau persentase $100 \%$, maka nilai $100 \%$ dikurangi dengan $64,8 \%$ adalah $35,2 \%$ dinyatakan tidak dapat dijangkau pada penelitian ini.

\section{PEMBAHASAN}

Terkait dengan tujuan penelitian ini, dinyatakan bahwa pada variabel Digital Marketing (X1) tidak memiliki pengaruh terhadap variabel penjualan produk (Y). 
Penyebab tidak memiliki pengaruh berdasarkan hasil wawancara yang telah dilakukan oleh peneliti adalah pengrajin tahu sebagai responden belum terlalu fokus pada penjualan online. Masa pandemi penjualan tahu mengalalami penurunan yang drastis. Disisi, tidak pengaruhnya digital marketing juga tidak signifikan. Oleh sebab itu, penjualan produk tahu masih dapat dilakukan, meskipun pengurangan kegiatan produksi diperlukan. Indikator yang digunakan dalam digital marketing adalah site design, incentive program dan intercative.

Indikator penilaian ini menunjukkan jika nilai konsistensi sebesar $72 \%$. Dalam hal ini, nilai tersebut sudah dikategorikan memiliki tingkat konsistensi yang tinggi. Jika ini tidak berpengaruh tidak dimasalahkan karena nilai dari uji parsial sebesar $-0,008$ atau sebesar $0,008 \%$ yang dimana nilai tidak dapat memberikan pengaruh tidak mencapai $1 \%$. Penelitian ini searah dengan (Hendrawan et al., 2019), kemudian pada variabel Perceived quality (X2) memiliki pengaruh terhadap penjualan produk (Y). Penyebab adanya pengaruh adalah mutu produk tahu tersebut memang berkualitas jika ditinjau dari persepsi mutu pelanggan.

Pengrajin tahu sebagai produsen sudah memahami apa yang diinginkan oleh pelanggan terhadap produk tahu tersebut. Pengrajin tahu sebagai responden sudah memahami selera dari pelanggan jika menginginkan produknya dapat terjual selama masa pandemi ini. Di sisi lain, secara konsistensi pada jawaban yang diberikan oleh responden terkaiat Perceived Quality (X2) dengan nilai prosentase sebesar $82,9 \%$. Hal ini didukung dengan indikator yang digunakan yaitu durability, features, aesthetics, reliability, conformance dengan nilai uji parsial sebesar 2,874 yang dibandingkan dengan $\mathrm{T}$ tabel.

Nilai uji $\mathrm{T}$ lebih besar dari $\mathrm{T}$ tabel. Disimpulkan bahwa ada pengaruh pada variabel perceived quality terhadap penjualan produk. Selanjutnya adalah variabel Personal Selling (X3) memiliki pengaruh terhadap variabel penjualan produk (Y). Pengaruh yang diberikan secara parsial bernilai 6,605 yang nilai tersebut melebihi nilai $\mathrm{T}$ tabel, kemudian jika ditinjau secara tingkat signifikan, pengaruh yang diberikan sangat signifikan karena nilai sig. sebesar 0,000.

Sisi lain, tingkat konsistensi sebesar $51,2 \%$, di mana nilai tersebut sangat konsisten karena melebihi 50\%. Penelitian ini searah dengan (Husnus \& Pratiwi, 2014). Variabel digital marketing (X1), perceived quality (X2) dan personal selling (X3) memiliki pengaruh yang signifikan terhadap penjualan produk (Y). Dalam hal ini pengaruh yang diberikan ada dukungan indikator pada penjualan produk antara lain karakteristik produk tahu, jasa yang ditawarkan dan kesesuaian harga.

Meskipun terancam menurunkan kapasitas produksi selama masa pandemi ini, pengrajin tahu tetap memanfaatkan secara baik peluang yang ada, sehingga terjadi penurunan pendapatan tidak dimasalahkan, karena yang terpenting proses produksi pada lokasi pengrajin tahu yang diteliti tetap operasi setiap harinya. Ditinjau dari tingkat keberhasilan penelitian, mengacu pada nilai koefisien determinasi. Nilai tersebut sebesar $64,8 \%$, artinya variabel digital marketing (X1), perceived quality (X2) dan personal selling (X3) dapat menjelaskan nilai kesamaan pada penjualan produk (Y) tahu di kota dan kabupaten kediri.

\section{SIMPULAN}

Secara parsial, digital marketing (X1) tidak berpengaruh terhadap penjualan produk (Y), perceived quality (X2) berpengaruh terhadap penjualan produk (Y) dan personal selling (X3) berpengaruh terhadap penjualan produk (Y), sedangkan secara simultan digital marketing (X1), perceived quality (X2) dan personal selling (X3) memiliki pengaruh terhadap penjualan produk (Y). Tingkat keberhasilan penelitian sebesar $64,8 \%$. Saran yang dapat diberikan untuk peneliti selanjutnya adalah diperlukan penambahan sampel penelitian untuk mendapatkan hasil wawancara yang akurat. Bagi pembaca dapat digunakan sebagai referensi di dalam bidang manajemen ekonomi.

\section{DAFTAR PUSTAKA}

Alfianika, N. (2018). Metode Penelitian Pengajaran Bahasa Indonesia. In CV Budi Utama.

Andarini, M., Laely, N., \& Laily, N. (2020). Analisis Harga , Inovasi Produk , Promosi dan Proses Bisnis Terhadap Kepuasan Konsumen Bakso Aci Tata Snack. 05.

Andrew, S. (2016). A Thematic Exploration of Digital, Social Media, and Mobile Marketing: Research Evolution from 
2000 to 2015 and an Agenda for Future Inquiry. Journal of Marketing, 80, 146.

Andriani, D. P. (2017). Validitas dan reliabilitas skala. Universitas Brawijaya, pp. 1-39. Retrieved from http://www.ncbi.nlm.nih.gov/pubmed/15 350854

Budijanto, D. (2013). Populasi, Sampling, dan Besar Sampel. Kementerian Kesehatan RI.

Crick, J. M., \& Crick, D. (2020). Coopetition and COVID-19: Collaborative businessto-business marketing strategies in a pandemic crisis. Industrial Marketing Management, 88(May), 206-213. https://doi.org/10.1016/j.indmarman.202 0.05 .016

Dahlan, M. S. (2010). Besar Sampel dan Cara Pengambilan Sampel dalam Penelitian Kedokteran dan Kesehatan. In Salemba Medika.

Das, G. (2014). Linkages of retailer personality, perceived quality and purchase intention with retailer loyalty: A study of Indian non-food retailing. Journal of Retailing and Consumer Services, 21(3), 407-414. https://doi.org/https://doi.org/10.1016/j.jr etconser.2013.11.001

Djunaedi. (2016). Pengaruh Corporate Social Responsibility (CSR), dan Kualitas Produk Terhadap, Citra Bank dan Keputusan Menabung di BNI Syariah Kota Kediri. JMM17: Jurnal Ilmu Ekonomi Dan Manajemen, 3(02). Retrieved from http://jurnal.untagsby.ac.id/index.php/jmm17/article/view/8 $05 / 727$

Donthu, N., \& Gustafsson, A. (2020). Effects of COVID-19 on business and research. Journal of Business Research, 117(June), 284-289.

https://doi.org/10.1016/j.jbusres.2020.06. 008

Field, A. (2013). Discovering statistics using IBM SPSS statistics.

Field, Andy. (2013). Discovering statistics using IBM SPSS statistics. In Statistics.

Gilad, A., \& Slovin, H. (2015). Population responses in V1 encode different figures by response amplitude. Journal of Neuroscience. https://doi.org/10.1523/JNEUROSCI.097 $1-14.2015$
Hasanah, H. (2017). TEKNIK-TEKNIK OBSERVASI (Sebuah Alternatif Metode Pengumpulan Data Kualitatif Ilmu-ilmu Sosial). At-Taqaddum, 8(1), 21. https://doi.org/10.21580/at.v8i1.1163

Hendrawan, A., Sucahyowati, H., Cahyandi, K., Indriyani, \& Rayendra, A. (2019). Pengaruh Marketing Digital Terhadap Kinerja Penjualan Produk UMKM Asti Gauri di Kecamatan Bantasari Cilacap. Jurnal Administrasi Dan Kesekretarisan, 4(1), 53-60. Retrieved from http://www.jurnal.stiks-

tarakanita.ac.id/index.php/JAK/article/vie $\mathrm{w} / 189 / 136$

Hong, Y., Cai, G., Mo, Z., Gao, W., Xu, L., Jiang, Y., \& Jiang, J. (2020). The impact of covid-19 on tourist satisfaction with b\&b in zhejiang, china: An importanceperformance analysis. International Journal of Environmental Research and Public Health, 17(10). https://doi.org/10.3390/ijerph17103747

Husnus, Y., \& Pratiwi, A. I. (2014). Pengaruh Personal Selling Terhadap Peningkatan Penjualan Produk Double Pan Pada Pt Dahlia Dewantara Bogor. Jurnal Ilmiah Manajemen Dan Akuntansi Fakultas Ekonomi (JIMAFE), 1, 70-77.

Indrasari, L. (2017). Analisis Pengaruh Retail Marketing Mix Terhadap Loyalitas Konsumen Pada Pasar Modern (Studi Kasus pada Indomaret Bandar Kediri). JATI UNIK : Jurnal Ilmiah Teknik Dan Manajemen Industri, 1(1), 47. https://doi.org/10.30737/jatiunik.v1i1.71

Janie, A. D. . (2012). Statistik Deskripstif dan Regresi Linier Berganda dengan SPSS. In Statistik Deskripstif dan Regresi Linier Berganda dengan SPSS.

Junusi, R. El. (2020). Digital Marketing During the Pandemic Period; A Study of Islamic Perspective. Journal of Digital Marketing and Halal Industry, 2(1), 15-28.

Komari, A. (2017). The Influence of Environment and Managerial Capacity on Funding Decisions for Small Crafts Enterprises in East Java. 4(1).

Komari, A., Laely, N., \& Panjaitan, H. (2017). Marketing Performance Analysis by Customer Relationship Marketing , Market Orientation, and The Image of Islamic Banks in Kediri , East Java , Indonesia. 6(3), 1-9. 
Komari, A., Sularso, A., \& Sumiato. (2019). Influence of Marketing Mix against Marketing Performance Through the Orientation of the Batik Small Industry Market In East Java. International Journal of Business and Management Invention (IJBMI), 8(04), 13.

Kotler, P. (2011). Reinventing marketing to manage the environmental imperative. Journal of Marketing. https://doi.org/10.1509/jmkg.75.4.132

Laely, N. (2020). Strategi Pemasaran Usaha Kecil "Industri Makanan di Jawa Timur." Kediri.

Lawendatu, J., Kekenusa, J. S., \& Hatidja, D. (2014). Regresi Linier Berganda Untuk Menganalisis Pendapatan Petani Pala. D'CARTESIAN.

https://doi.org/10.35799/dc.3.1.2014.399 8

Maksum, A. (2012). Data, Teknik Pengumpulan Data dan Instrumen Penelitian. Jurnal Cakrawala Kependidikan, (agustus), 107.

Ocon, J. A. C., \& Alvarez, M. G. (2014). The Implication of Personal Selling Strategies in Motivation, Approaches and Good Grooming. Procedia - Social and Behavioral Sciences, 155(October), 5357.

https://doi.org/10.1016/j.sbspro.2014.10. 255

Panjaitan, H., \& Djunaedi. (2017). Product Advantage , Customer Relationship Marketing , and Service Quality on Customer Satisfaction of Bank Syariah Mandiri in Surabaya. International Review of Management and Marketing, 7(4), 122-130.

Panjaitan, H., \& Laely, N. (2017). The Role of Relationship Marketing, and Satisfaction As Variable Mediation: Study at Bank BPR UMKM East Java in Surabaya. International Review of Management and Marketing, 7(5), 105-112.

Patel, J., \& Malpani, A. (2020). Impact of COVID-19 on research. International Journal of Advanced Science and Technology, 29(12s), 1774-1779. https://doi.org/10.1302/20463758.98.BJR-2020-0344

Patricia, D. (2016). B2B Commitment Building in Emerging Markets: The Case of Brazil.
Journal of Personal Selling \& Sales Management, 36, 105.

Purnamaningsih, N., \& Djunaidi. (2018). IbM Usaha Mikro Gula Merah Tebu Di Desamangunrejo Kecamatan Ngadiluwih Dan Desa Cendono Kecamatan Kandat Kabupaten Kediri. Jurnal Abdi Masyarakat, 1(1), 1-17.

Ramadhan, M. D., \& Muthohar, M. (2019). The influence of perceived price, perceived quality, brand image, and store image on the purchase intention of Hypermart private label. 308(Insyma), 140-143. https://doi.org/10.2991/insyma-19.2019.36

Rufaida, N. (2019). Analisis Pengaruh Pemasaran Digital (Digital Marketing) Terhadap Brand Awareness Pada ECommerce. E-Proceeding of Management :, 6(2), 2091. Retrieved from https://libraryeproceeding.telkomuniversity .ac.id/index.php/management/article/view/ 9529/9399

Sugiyono. (2014). Teknik Pengumpulan Data. Metode Penelitian Kuantitatif, Kualitatif Dan R\&D, 137. https://doi.org/10.3354/dao02420

Suryana. (2010). Metodologi Penelitian: Metodologi Penelitian Model Prakatis Penelitian Kuantitatif dan Kualitatif. In Universitas Pendidikan Indonesia. https://doi.org/10.1007/s13398-014-01737.2

Syafruddin, M., Hakim, L., \& Despa, D. (2014). Metode Regresi Linier Untuk Prediksi Kebutuhan Energi Listrik Jangka Panjang (Studi Kasus Provinsi Lampung). Jurnal Informatika.

Tavassoli, M., Saen, R. F., \& Zanjirani, D. M. (2020). Assessing sustainability of suppliers: A novel stochastic-fuzzy DEA model. Sustainable Production and Consumption, 21, 78-91. https://doi.org/10.1016/j.spc.2019.11.001 